\title{
PET/CT vs CECT in assessment of therapeutic response in lymphoma
}

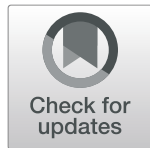

\author{
Aya Yassin ${ }^{*}$ (D, Radwa Hany El Sheikh and Mona Mohamed Ali
}

\begin{abstract}
Background: Lymphoma incorporates histologically variable cancers derived from the immune system cells. The distinctive feature of lymphoma is the rapid increase in size and number of lymph nodes and/or secondary lymphoid tissues.

The aim of the work is to evaluate the accuracy of PET/CT vs CECT in the assessment of response to therapy in lymphoma patients: both early and late therapeutic response assessment.

This retrospective study was conducted on 80 patients with different types of lymphoma recruited and enrolled from a university hospital. All 80 patients underwent pre-treatment, during the course of chemotherapy and at the end of planned treatment contrast-enhanced $C T$ (CECT) and PET-CT. Interpretation of the CECT and the fusion images PET/CT each was done separately and comparison of the results was achieved.

Results: PET/CT and contrast-enhanced computed tomography were concurrent in results in $55 \%$ of cases during treatment and $75 \%$ at the end of treatment with CT sensitivity of $61.1 \%$, specificity of $92.2 \%$, and accuracy of $76.2 \%$ during treatment in comparison to $100 \%$ sensitivity and specificity of PET/CT. Sensitivity of CT at end of treatment was $57.5 \%$, specificity $86.7 \%$, and accuracy $71.6 \%$ as compared to $100 \%$ sensitivity and specificity of PET/CT.

Conclusion: PET/CT using 2-deoxy-2-[18F] fluoro-D-glucose is considered one of the best oncologic imaging modalities at the time being with valuable applications in lymphoma. It is very efficient with least possible pitfalls and false results compared to either of its components alone and to side by side reading of separately acquired PET and CT. PET/CT can detect both anatomical information as well as metabolical information providing more data and thus giving more accurate results than CECT. It is becoming a standard modality for lymphoma providing a new vision to management and treatment plan.
\end{abstract}

Keywords: Therapeutic response, Lymphoma, PET/CT, CECT

\section{Background}

Lymphoma incorporates over 50 biologically and histologically different types of lymphoid malignancies. Lymphoma is classified into Hodgkin lymphoma (HL) and non-Hodgkin lymphoma (NHL) [1].

The metabolic response to therapy can be detected in the interim PET after a few cycles of chemotherapy and in endof-treatment (EOT) PET. The 18F-fluorodeoxyglucose uptake markedly decreases with reduction in the SUV when the tumoral cells respond to therapy [2].

\footnotetext{
* Correspondence: ayassin@hotmail.com Egypt

Radiology Department, Faculty of Medicine, Ain Shams University, Cairo,

(C) The Author(s). 2020 Open Access This article is licensed under a Creative Commons Attribution 4.0 International License, which permits use, sharing, adaptation, distribution and reproduction in any medium or format, as long as you give appropriate credit to the original author(s) and the source, provide a link to the Creative Commons licence, and indicate if changes were made. The images or other third party material in this article are included in the article's Creative Commons licence, unless indicated otherwise in a credit line to the material. If material is not included in the article's Creative Commons licence and your intended use is not permitted by statutory regulation or exceeds the permitted use, you will need to obtain permission directly from the copyright holder. To view a copy of this licence, visit http://creativecommons.org/licenses/by/4.0/. widely used imaging techniques to evaluate both early and late treatment response during as well as after therapy in patients suffering from lymphomas [3].

PET/CT using (18F) FDG is considered one of the functional imaging techniques used to assess the glucose metabolism in vivo; its use has been widely increased in the evaluation of oncology patients being highly sensitive in assessment of malignancy as PET/CT can detect malignancy prior to morphological changes [4].

In daily practice, PET/CT is used in patients suffering from both HL and NHL to evaluate the sensitivity to 
chemotherapy in the "interim" PET/CT and to predict the clinical outcome post-therapy [5].

At the end of treatment, residual masses are commonly detected on CT scan, but PET/CT can differentiate between viable pathological cells and nonviable fibrotic scar tissue with high accuracy [6].

The response to therapy is assessed according to the metabolic activity of target lesions using a 5-point scale (5-PS) known as the DC [7].

\section{Methods}

\section{Subjects}

This retrospective study was conducted on 80 patients with different types of lymphoma recruited and enrolled from a university hospital. Patients underwent pretreatment PET-CT, during the course of chemotherapy and at the end of planned treatment or for relapsed /refractory disease prior to new treatment according to the protocol at our hospital (Fig. 1).

\section{Ethics approval and consent to participate}

Not applicable. This was a retrospective study. We collected the data from the records of the patients and the institutional review board waived the requirement for informed patient consent.

The inclusion criteria are as follows:

1. Patients with pathologically proved lymphoma (different types)

2. No age or sex predilection

The exclusion criteria are as follows:

1. History of atopic disorders

2. Patients with renal function impairment (with serum creatinine $>2 \mathrm{mg} / \mathrm{dl}$ )

\section{Technique of PET/CT}

Specific information required for optimal interpretation of CECT and FDG PET/CT images, such as clinical history; results of previous imaging studies; and history of surgery, chemotherapy, or radiation therapy, were obtained.

A thorough explanation of the procedure was given to the patient and consent was obtained.

Patients underwent pre-treatment PET-CT, during the course of chemotherapy and at the end of planned treatment or for relapsed/refractory disease prior new treatment according to the protocol at our hospital.

The study was conducted in PET/CT unit at Ain Shams University hospitals on GE PET-CT Discovery IQ 5 Rings machine with Dual Acquisition Channels, 50slice equivalent CT speed with IQE 1.75 pitch booster, $20 \mathrm{~mm}$ CT coverage, and Q-clear attenuation correction.

Patients fasted for at least $6 \mathrm{~h}$ before the examination but were asked to drink water to maintain good hydration if anesthesia or sedation was not indicated and blood glucose levels were less than $200 \mathrm{mg} / \mathrm{dL}$. A dose of 6-7 MBq/ $\mathrm{kg}(0.1 \mathrm{mCi} / \mathrm{kg}$, minimum $3 \mathrm{mCi})$ FDG was injected intravenously. The patients rested in a quiet room. After the 45-60-min uptake period, the patients were taken for the PET-CT study. CECT from the skull to the mid-thigh was performed by using a 16detector row CT scanner. Intravenous bolus injection of a non-ionic iodinated contrast material at a dose of $2-3 \mathrm{~mL} / \mathrm{kg}$ of body weight was performed just before initiation of scanning. Scanning protocols with $120 \mathrm{kVp}$ and effective tube current that varied from 120 to $160 \mathrm{mAs}$ were used.

After CT acquisition, PET acquisition of the same axial range began with the patient in the same position on the table for 2-3 min per bed position with bed overlapping slice acquisition. PET data were acquired by

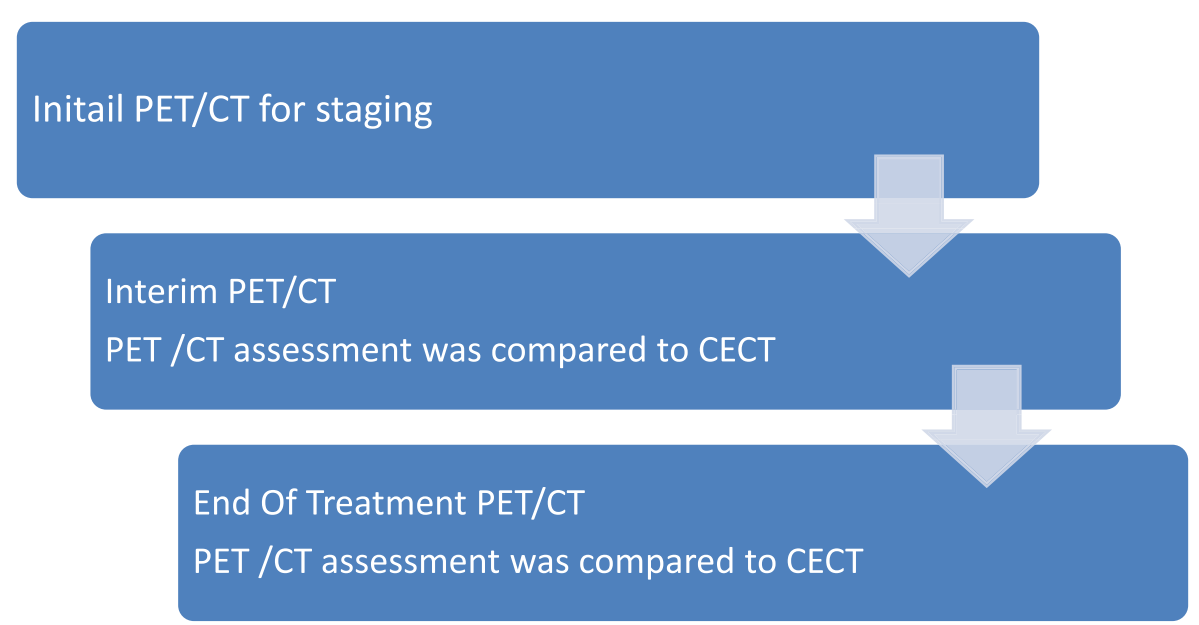

Fig. 1 Flowchart of the research methodology 
Table 1 Lugano Criteria for Response Assessment on CT and FDG-PET/CT [8]

\begin{tabular}{|c|c|c|c|c|c|}
\hline Modality & Clinical Application & Complete Response & $\begin{array}{l}\text { Partial Remission/ } \\
\text { Partial Response }\end{array}$ & $\begin{array}{l}\text { Stable Disease/ } \\
\text { No Response }\end{array}$ & Progressive Disease \\
\hline CT & $\begin{array}{l}\text { All lymphoma (if CT } \\
\text { is performed for } \\
\text { tumor size } \\
\text { measurement); } \\
\text { primary assessment } \\
\text { modality for non- } \\
\text { FDG-avid } \\
\text { lymphoma }\end{array}$ & $\begin{array}{l}\text { Complete radiologic } \\
\text { response: } \\
\text { Nodal sites reduced to } \\
\leq 1.5 \mathrm{~cm} \text { in LDi } \\
\text { Complete } \\
\text { disappearance of } \\
\text { radiologic evidence } \\
\text { of disease }\end{array}$ & $\begin{array}{l}\text { Partial remission: } \\
\text { For multiple lesions, } \\
\geq 50 \% \text { decrease in } \\
\text { SPD of up to six target } \\
\text { measurable nodes and } \\
\text { extranodal sites } \\
\text { If only a single lesion } \\
\text { is present, } \geq 50 \% \\
\text { decrease in the PPD }\end{array}$ & $\begin{array}{l}\text { Stable disease: } \\
<50 \% \text { decrease } \\
\text { from baseline in } \\
\text { SPD of up to } \\
\text { six dominant, } \\
\text { measurable } \\
\text { nodes and } \\
\text { extranodal sites; } \\
\text { no criteria for } \\
\text { progressive } \\
\text { disease are met }\end{array}$ & $\begin{array}{l}\text { May be based on a single dominant lesion; } \\
\text { progressive disease is assigned with at least } \\
\text { one of the following: } \\
\text { 1. New or increased adenopathy; an individual node } \\
\text { must be abnormal with: } \\
\text { (a) LDi }>1.5 \mathrm{~cm} \text { AND } \\
\text { (b) PPD increase by } \geq 50 \% \text { from nadir AND } \\
\text { (c) LDi or SDi increase from nadir; the increase } \\
\text { in LDi or SDi from nadir (the smallest recorded } \\
\text { measurement) must be }>0.5 \mathrm{~cm} \text { for lesions } \\
\leq 2 \mathrm{~cm} \text { and }>1.0 \mathrm{~cm} \text { for lesions }>2 \mathrm{~cm} \\
\text { 2. Splenic volume increase: } \\
\text { (a) With prior splenomegaly: increase in length } \\
\text { by }>50 \% \text { of its prior increase beyond } \\
\text { baseline; for example, splenic length increases } \\
\text { from } 15 \mathrm{~cm} \text { ( } 2 \mathrm{~cm} \text { above baseline splenomegaly } \\
\text { of } 13 \mathrm{~cm} \text { ) to }>16 \mathrm{~cm} \text { ( }>3 \mathrm{~cm} \text { above baseline) } \\
\text { (b) Without prior splenomegaly: length increase } \\
\text { by at least } 2 \mathrm{~cm} \\
\text { (c) New or recurrent splenomegaly } \\
\text { 3. New or larger nonmeasured lesions } \\
\text { 4. Recurrent previously resolved lesions } \\
\text { 5. New extranodal lesion }>1 \mathrm{~cm} \text { in any axis } \\
\text { (new lesions }<1 \mathrm{~cm} \text { in any axis are included } \\
\text { if these are "unequivocally attributable" } \\
\text { to lymphoma) } \\
\text { 6. A new node }>1.5 \mathrm{~cm} \text { in any axis }\end{array}$ \\
\hline $\begin{array}{c}\text { FDG PET/ } \\
\text { СT }\end{array}$ & $\begin{array}{l}\text { FDG-avid lymphoma } \\
\text { (including Hodgkin } \\
\text { lymphoma and } \\
\text { diffuse large B-cell } \\
\text { lymphoma) }\end{array}$ & $\begin{array}{l}\text { Complete metabolic } \\
\text { response: } \\
\text { Score of } 1,2,3 \text { in } \\
\text { nodal or extranodal } \\
\text { sites with or } \\
\text { without a residual } \\
\text { mass }\end{array}$ & $\begin{array}{l}\text { Partial metabolic } \\
\text { response: } \\
\text { Score of } 4 \text { or } 5 \text { with } \\
\text { reduced uptake } \\
\text { compared with } \\
\text { baseline and residual } \\
\text { mass(es) of any size }\end{array}$ & $\begin{array}{l}\text { No metabolic } \\
\text { response: } \\
\text { Score of } 4 \text { or } 5 \\
\text { with no obvious } \\
\text { change in FDG } \\
\text { uptake }\end{array}$ & $\begin{array}{l}\text { Score } 4 \text { or } 5 \text { in any lesion with an increase in } \\
\text { intensity of uptake from baseline } \\
\text { and/or } \\
\text { New FDG-avid foci consistent with lymphoma }\end{array}$ \\
\hline
\end{tabular}

Table $\mathbf{2}$ The five-point scale used to assess treatment response by FDG PET/CT

\begin{tabular}{ll} 
Score & Description \\
\hline 1 & No uptake \\
2 & Uptake $\leq$ mediastinum \\
3 & Uptake $>$ mediastinum but $\leq$ liver \\
4 & Uptake moderately increased \\
& above liver at any site \\
5 & Markedly increased uptake \\
& above liver at any site \\
$\mathrm{NE}$ & Not evaluable \\
$\mathrm{X}$ & Any areas of uptake not likely to \\
& be related to lymphoma \\
\hline
\end{tabular}

Note: Data from Cheson et al. ${ }^{10}$ 
using a matrix of $128 \times 128$ pixels. CT-based attenuation correction of the emission images was used. After PET data acquisition was completed, the reconstructed attenuation-corrected PET images, CT images, and fused images of matching pairs of PET and CT images were available for review in axial, coronal, and sagittal planes, as well as in maximum intensity projections and in three-dimensional cine mode.

\section{Image analysis}

Interpretation of the CECT (contrast-enhanced CT) and the fusion images PET/CT each was done by two radiologists with 5 and 10 years' experience and consensus decision was used for the study.

\section{CECT assessment}

A lymph node was considered suspicious if it lost its fatty central hilum, became more rounded than ovoid, and attained peripheral rather than central vascularity with a maximum diameter greater than $1.5 \mathrm{~cm}$. An enlarged spleen was considered one sign of splenic involvement in lymphoma with the upper cut off value for its vertical length of $13 \mathrm{~cm}$. This together with focal splenic lesions or military infiltration was suggestive of splenic involvement. Four categories for CT have been outlined: (a) complete radiologic response, all nodes less than or equal to $1.5 \mathrm{~cm}$ in longest diameter, and disappearance of all CT findings of lymphoma; (b) partial remission, $50 \%$ or greater decrease in disease burden; (c) stable disease, less than $50 \%$ decrease in disease burden; and (d) progressive disease, new or increased adenopathy or new extra nodal lymphoma [8].

\section{PET assessment}

Any focus of elevated FDG metabolism in comparison with liver and mediastinum, not located in areas of normal FDG uptake, was considered to be abnormal. Visual inspection was used routinely for assessment and SUV is used in assessing questionable lesions. The areas of FDG uptake were localized anatomically on CT scans. In our study, we evaluate the response

Table 3 Demographic data distribution of the study group

\begin{tabular}{lll}
\hline & Number & Percent \\
\hline Sex & 12 & 60.0 \\
$\quad$ Female & 8 & 40.0 \\
$\quad$ Male & & \\
Age (years) & 10 & 50.0 \\
$\quad \leq 35$ years & 10 & 50.0 \\
$>35$ years & $18-64[35.35 \pm 14.06]$ & \\
Range [mean $\pm S D]$ &
\end{tabular}

Table 4 Lymphoma subtypes of the enrolled study group

\begin{tabular}{lll}
\hline & Number & Percent \\
\hline Type & 12 & \\
HL & 8 & 60.0 \\
NHL & & 40.0 \\
Subtype & 1 & \\
Anaplastic & 5 & 5.0 \\
B cell & 7 & 25.0 \\
Large B cell & 3 & 35.0 \\
Mixed cellular & 1 & 15.0 \\
NLPHL & 3 & 5.0 \\
Nodular sclerosis & & 15.0 \\
\hline
\end{tabular}

according to the new Lugano criteria for using CT and FDG PET/CT (Table 1).

The five-point scale (Table 2) is now applied to both interim and end-of-treatment FDG PET/CT response assessment. Four categories of response have been outlined as follows: (a) complete metabolic response-score of 1, 2, or 3; (b) partial metabolic response-score of 4 or 5 with reduced FDG uptake; (c) no metabolic response-score of 4 or 5 without significant change in FDG uptake; and (d) progressive metabolic diseasescore of 4 or 5 with increased FDG uptake or with new lesions [8]. Comparison between fused PET-CT images findings and the contrast-enhanced CT study findings was done. The results were tabulated and statistically analyzed.

\section{Data management and analysis Statistical analysis}

Recorded data were analyzed using the statistical package for social sciences, version 20.0 (SPSS Inc., Chicago, IL, USA). Quantitative data were expressed as mean \pm standard deviation (SD). Qualitative data were expressed as frequency and percentage.

The following tests were done:

Table 5 Treatment assessment distribution of the study group

\begin{tabular}{lll}
\hline CT & Number & Percent \\
Complete regression & 3 & 15.0 \\
Progression disease & 2 & 10.0 \\
Partial regression & 15 & 75.0 \\
Stationary disease & 0 & 0.0 \\
PET & & \\
Complete regression & 12 & 60.0 \\
Progression disease & 2 & 10.0 \\
Partial regression & 6 & 30.0 \\
Stationary disease & 0 & 0.0 \\
\hline
\end{tabular}


Table 6 Relation between treatment assessment at CT and treatment assessment at PET-CT of the study group

\begin{tabular}{|c|c|c|c|c|c|c|c|c|c|c|}
\hline \multirow{3}{*}{$\begin{array}{l}\text { Treatment } \\
\text { assessment PET }\end{array}$} & \multicolumn{6}{|c|}{ Treatment assessment at CT } & \multirow{2}{*}{\multicolumn{2}{|c|}{ Total }} & \multirow{2}{*}{\multicolumn{2}{|c|}{ Chi-square test }} \\
\hline & \multicolumn{2}{|c|}{ Complete regression } & \multicolumn{2}{|c|}{ Progression disease } & \multicolumn{2}{|c|}{ Partial regression } & & & & \\
\hline & No. & $\%$ & No. & $\%$ & No. & $\%$ & No. & $\%$ & $x^{2}$ & $P$ value \\
\hline Complete regression & 3 & 15.0 & 0 & 0.0 & 9 & 45.0 & 12 & 60.0 & 22.582 & $<0.001^{* *}$ \\
\hline Progression disease & 0 & 0.0 & 2 & 10.0 & 0 & 0.0 & 2 & 10.0 & & \\
\hline Partial regression & 0 & 0.0 & 0 & 0.0 & 6 & 30.0 & 6 & 30.0 & & \\
\hline Stationary disease & 0 & 0.0 & 0 & 0.0 & 0 & 0.0 & 0 & 0.0 & & \\
\hline Total & 3 & 15.0 & 2 & 10.0 & 15 & 75.0 & 20 & 100.0 & & \\
\hline
\end{tabular}

$X^{2}$, Chi-square test; ${ }^{* *} P$ value $<0.001 \mathrm{HS}$

1. Chi-square $\left(\chi^{2}\right)$ test of significance was used in order to compare proportions between qualitative parameters.

2. Pearson's correlation coefficient $(r)$ test was used to assess the degree of association between two sets of variables

3. The confidence interval was set to $95 \%$ and the margin of error accepted was set to $5 \%$. So the $P$ value was considered significant as follows:
(a) Probability ( $P$ value)
(b) $P$ value $\leq 0.05$ was considered significant.
(c) $P$ value $\leq 0.001$ was considered highly significant.

(d) $P$ value $>0.05$ was considered insignificant.

\section{Results}

A total of 80 patients with variable ages and different stages of different types of lymphoma were enrolled during the study period.

There were 32 male cases $40 \%$ and 48 female cases $60 \%$. The age ranged from 18 to 64 years with mean $35.35 \pm 14.06$ (Table 3 ). Sixty percent of our cases were HL and $40 \%$ were NHL (Table 4 ).

All 80 patients underwent pre-treatment, during the course of chemotherapy and at the end of planned treatment CECT and PET-CT.
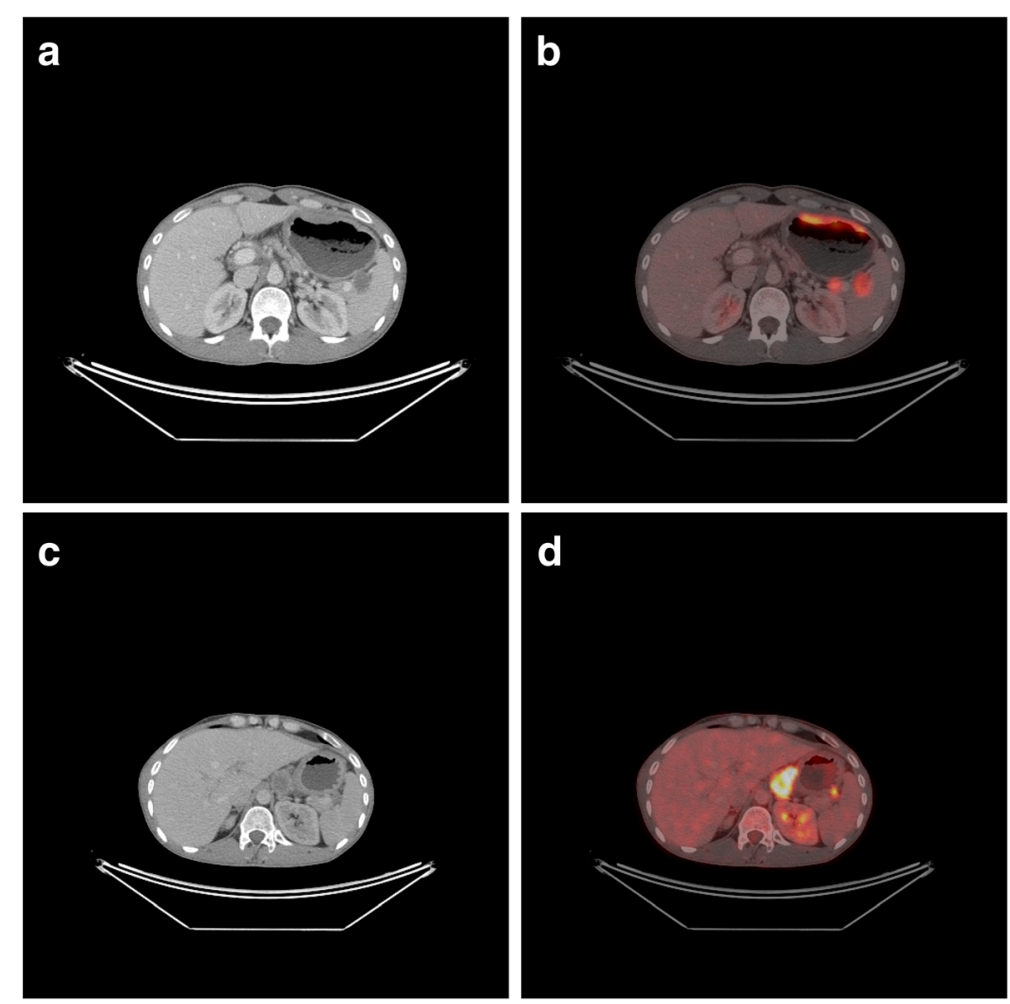

Fig. 2 A 29-year-old male, known case of gastric antrum and body B cell lymphoma, received CTH, the last session 2 weeks ago with irrelevant surgical history. a, b His initial PET/CT compared to his interment study revealed splenic hilar lymph node measuring $16 \times 19 \mathrm{~mm}$ with SUV 9.6. C, d His interment study revealed no size change compared to the previous study yet reduced SUV max to be 8.9. This case was stationary by CT while regressive by PET 
In first follow-up during the course of chemotherapy, out of the 80 cases, 18F-FDG PET/CT and CECT were concurrent in results in 44 out of the 80 cases (55\%) and discordant in the other cases $(45 \% n=36)$ detailed as follows: CECT detected complete regression in 12 cases (15\%), partial regression in 60 cases $(75 \%)$, stationary course in 0 cases $(0 \%)$, and progression in 8 cases $(10 \%)$, while 18F-FDG PET/CT detected complete regression in 48 cases $(60 \%)$, partial regression in 24 cases $(30 \%)$, stationary course in 0 case $(0 \%)$, and progression in 8 case (10\%) (Tables 5 and 6). In one of these cases, the initial $\mathrm{PET} / \mathrm{CT}$ compared to the interment study revealed stationary course as regards the size of the splenic hilar lymph yet with reduced SUV max. The course of the disease was stationary by $\mathrm{CT}$ while regressive by PET (Fig. 2). A residual mass was present in one of the cases on contrast-enhanced CT [partial response] without any uptake on PET (complete response) (Fig. 3). Thirty-six cases showed partial regression by $\mathrm{CT}$ and total regression by PET (Figs. 4 and 5).

At end of treatment assessment, CECT detected complete regression in 20 cases (25\%), partial regression in 16 cases (20\%), stationary course in 20 cases $(25 \%)$, and relapse in 24 cases (30\%), while 18F-FDG PET/CT detected complete regression in 36 cases (45\%), partial regression in 12 cases (15\%), stationary course in 4 cases (5\%), and disease relapse in 28 cases (35\%). There were statistically significant results in the follow-up of 6 months after the end of chemotherapy 18F-FDG PET/ CT study $(P$ value $=0.001)$. 18F-FDG PET/CT proved higher sensitivity and specificity over CECT in our study (Tables 7 and 8). In one of the cases, interim PET-CT showed right paratracheal enlarged lymph node on CT with no change in size, while PET CT images at end of therapy showed newly developed metabolic activity in it. The patient was categorized as stationary disease on CT and progressive disease on PET/CT (Fig. 6).

\section{Discussion}

Lymphoma consists of a heterogeneous group of diseases; marked improvement has been made in diagnosis and treatment. Imaging is important both for staging and assessment of response to therapy. Staging systems have been modified and specific criteria have been developed for assessment of response to therapy with both computed tomography (CT) and fluorine-18 fluorodeoxyglucose positron emission tomography (PET)/CT [8].

There are several common pitfalls in the diagnosis of lymphoma using PET alone. One of them is that gastric and cerebral lymphoma lesions are sometimes difficult to characterize on PET images due to physiologic gastric and cortical accumulation of FDG. Also, physiologic colonic uptake might be mistaken for lymphomatous infiltration. Another pitfall is that small-volume lesions might be undetectable on both pre- and post-therapy PET scans especially when there is high background activity
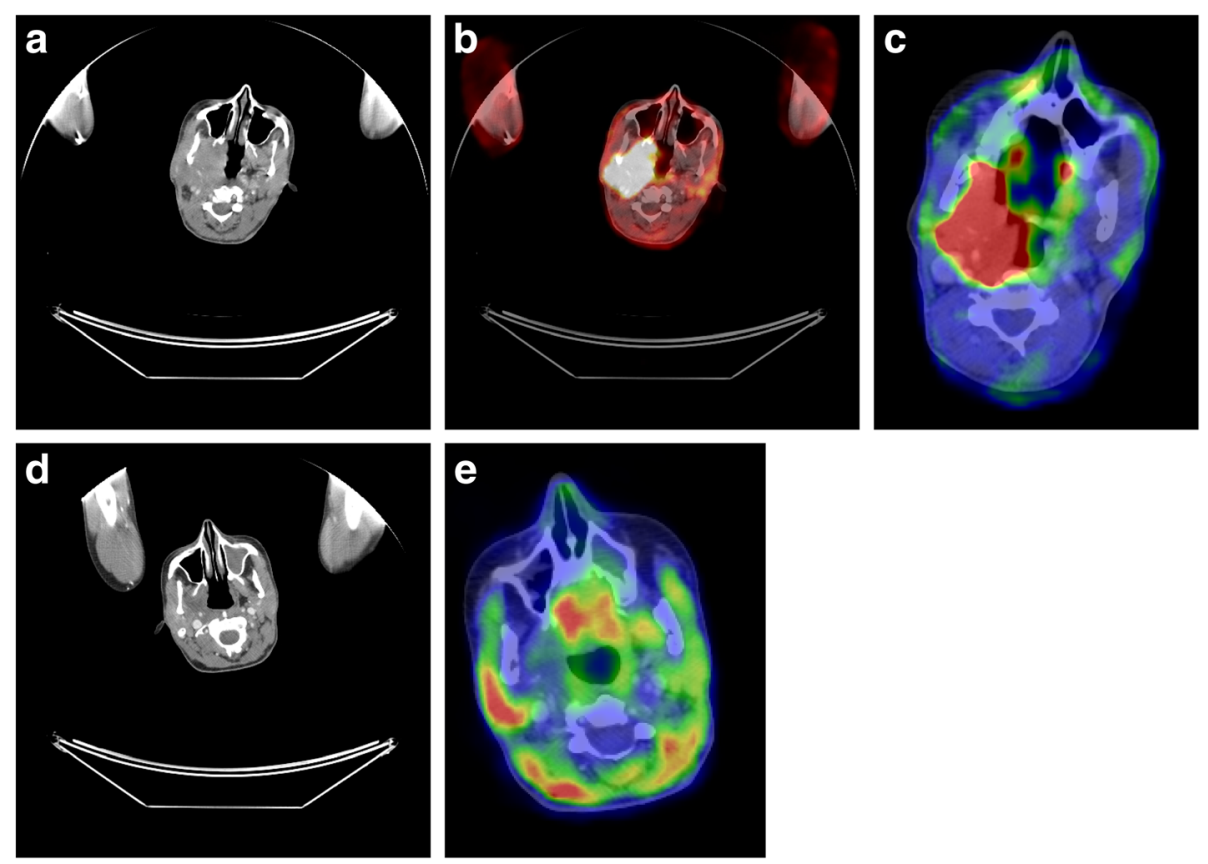

Fig. 3 A 25-year-old patient with large B cell lymphoma. a, b His initial study revealed a large ill-defined hypermetabolic right para-pharyngeal soft tissue mass lesion noted to be measuring about $5.7 \times 7 \times 7.5 \mathrm{~cm}$ achieving SUV max $\sim 11.1$. c, $\mathbf{d}$ His interment study revealed regressive course as regards the size of the previously reported soft tissue mass lesion roughly measuring about $2.5 \times 2.5 \times 5 \mathrm{~cm}$; the mass is non-FDG avid with total metabolic response. This case showed partial regression by $C T$ and total regression by PET/CT 

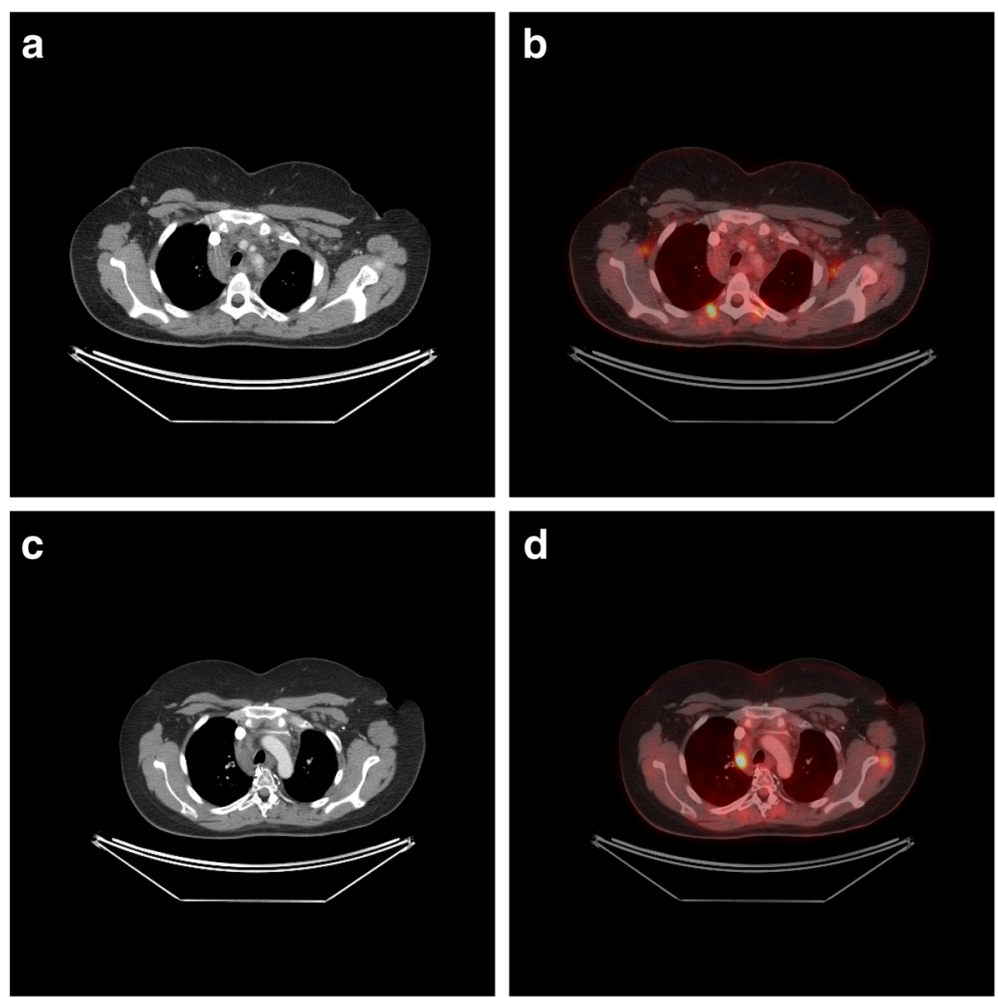

Fig. 4 A 34-year-old female patient known NHL. Interim PET-CT images $(\mathbf{a}, \mathbf{b})$ show subcentemetric non-metabolically active lymph node (arrows). PET CT images at end of therapy (c, d) showed no appreciable size change but with 18-FDG avid uptake. The patient was categorized as complete regression on CT and progressive on PET/CT

surrounding the lesions. Accurate correlation with anatomical CT findings is mandatory in avoiding such pitfalls; thus, integrated PET/CT is especially helpful [10].

Many reports in literature have assessed the role of $\mathrm{PET} / \mathrm{CT}$ for evaluation of therapeutic response of lymphoma.

In our study, we evaluated both PET/CT and CECT for their role in assessment of response during the course and end of treatment in lymphoma patients.

The imaging evaluation and follow-up of lymphoma patients in the past depended only on CECT findings. However, CECT has relatively low sensitivity in determining lymphomatous involvement of average-sized lymph nodes, bone marrow, spleen, and extranodal tissues. The presence of residual lymph node mass was a frequently encountered diagnostic dilemma as it was difficult to differentiate between post-treatment fibrosis and residual viable tumorous tissue by CECT [11].

In our study, PET/CT was able to add clinically significant information not obtained by CT. On a regional-based survey of patients, PET/CT showed significantly better results than CECT in accurately identifying lymph node groups as positive or negative for lymphomatous involvement. PET/CT was also capable of detecting more extranodal sites of the disease than CECT. PET/CT can assess therapeutic response more precisely than $\mathrm{CECT}$.

18F-FDG PET/CT does not depend only on nodal size to determine the presence or absence of malignancy (anatomical evaluation), assessment of intra-nodal activity plays a very important role (metabolic evaluation). Average-sized lymph nodes might contain tumoral tissue on 18F-FDG PET/CT images, and enlarged lymph nodes can be reactional in nature. Hence, for this reason, PET proved to be more sensitive and specific than CT for detection of sites of lymphomatous infiltration [12].

In the follow-up study during treatment, our study revealed that the results of PET and CT were concordant in 44 patients [12 complete responses (CR), 24 partial responses (PR), and 8 progressive diseases $(\mathrm{PD})]$. For the rest of the cases ( $45 \%$ of our cases, $n=36$ ), the therapeutic response was different.

While at the end of treatment assessment, the results of PET and CT were concordant in 52 patients [20 CR, $12 \mathrm{PR}$, and $20 \mathrm{PD}$ ]. For the rest of the cases (35\% of our cases, $n=28$ ), the therapeutic response differed. Thus, $\mathrm{PET} / \mathrm{CT}$ and contrast-enhanced computed tomography were concurrent in results in 55\% of cases during treatment and $75 \%$ at the end of treatment with CT sensitivity of $61.1 \%$, specificity of $92.2 \%$, and accuracy of $76.2 \%$ 

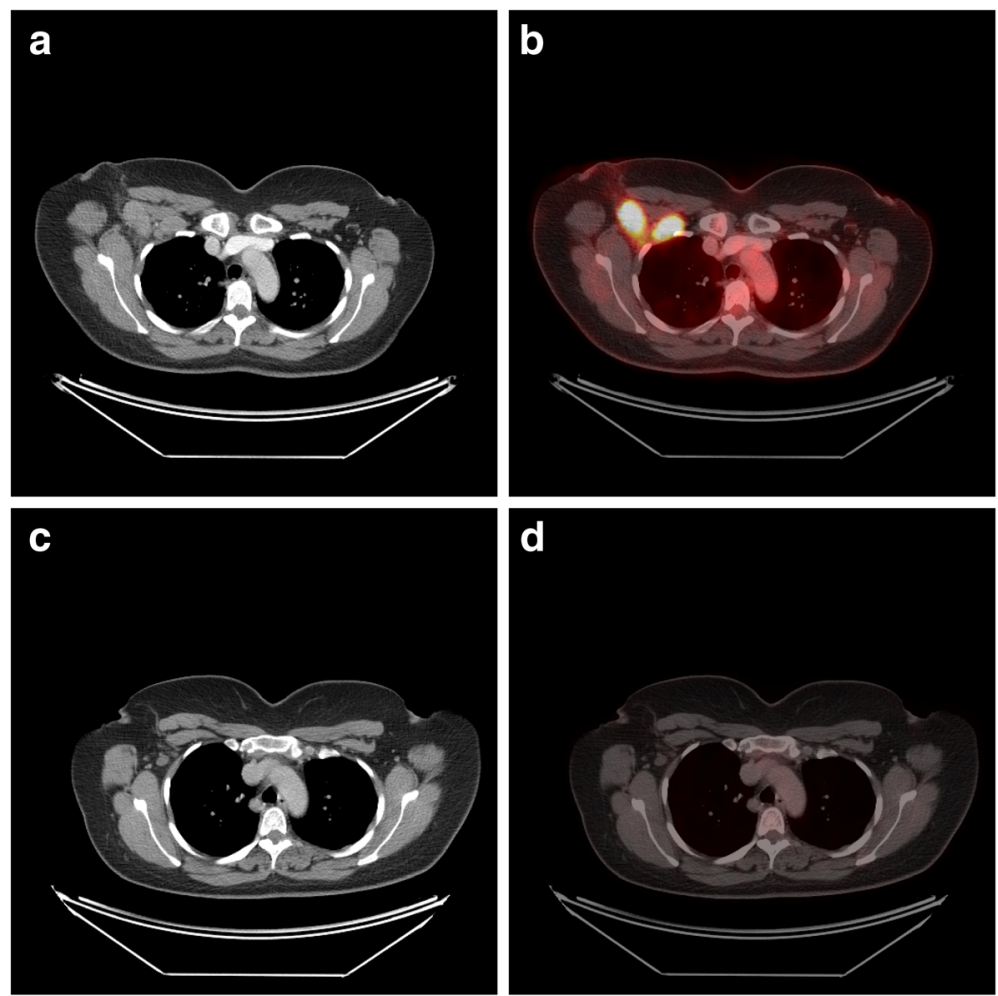

Fig. 5 A 37-year-old patient, newly diagnosed Hodgkin lymphoma. a, b His initial study revealed multiple metabolically active FDG avid lymph nodes which are seen at right axillary lymph nodes, largest measures $3.5 \times 2.6 \mathrm{~cm}$ with SUV max 7.05 . $\mathbf{c}$, $\mathbf{d}$ His interment study reveals complete metabolic resolution; however, anatomically still non-FDG avid axillary lymph nodes are noted that have markedly regressed in size; the largest measures $1.6 \times 0.65 \mathrm{~cm}$ compared to $3.5 \times 2.6 \mathrm{~cm}$ in previous study. This study was partial regression by $C T$ and total regression by PET

during treatment in comparison to $100 \%$ sensitivity and specificity of PET/CT, while sensitivity of CT at end of treatment is $57.5 \%$ with specificity of $86.7 \%$ and accuracy of $71.6 \%$. This is in keeping with the multicenter study; comparison of FDG PET/CT and 64-slice multidetector-row CT was done in initial staging and response evaluation at the end of treatment in patients with lymphoma by Gómez León et al. [13]; 181 patients were enrolled; their results confirmed that FDG PET/ CECT was clearly superior to ceCT64 for EOT evaluation $(P<0.05)$. Using FDG PET/CT, there was concordance with the reference standard in $97.8 \%$ of the cases $(88 / 90)$ with $\kappa=0.91(P<0.001)$, corresponding with a CR in $83.3 \%(n=75)$, a PR in $4.4 \%(n=4)$, and a PD in $10 \%(n=9)$, with good sensitivity and specificity for response assessment. As compared to CECT, there was concordance with the reference standard in $78 \%$ of cases (71/91).

Our results are also matching a study done by Othman et al. [14] were 100 patients were enrolled and showed poor agreement between PET/CT and CECTs $(k=0.32)$.

Similar results were also obtained in the study by Le Dortz et al. [15]. They retrospectively evaluated the usefulness of positron emission tomography/computed tomography in staging, prognosis evaluation and restaging of patients with follicular lymphoma. In 45 patients, the accuracy of PET/CT for therapeutic response assessment was higher than that of CT (0.97 vs 0.64$)$, especially due to its ability to identify inactive residual masses.

In a study by Omar et al. [11], the study included 50 patient PET/CTs in initial staging and therapy response assessment of lymphoma compared to contrastenhanced CT. In the follow-up study during chemotherapy cycles, 18F-FDG PET/CT and CECT were concurrent in results in 11 cases (61\%) and discordant in 7 cases (39\%). In the follow-up study after the end of chemotherapy cycles, 18F-FDG PET/CT and CECT were concurrent in results in 9 cases (44\%) and discordant in 11 cases (56\%).

In a study done by Najjar et al. [16], the sensitivity and specificity were $87 \%$ and $100 \%$ for FDG-PET, $100 \%$ and $100 \%$ for physical examination, and $90 \%$ and $100 \%$ for $\mathrm{CT}$, respectively. In addition, 42 of 97 peripheral lymph node lesions observed by FDG-PET were clinically undetected, whereas the physical examination detected 23 additional nodal lesions. PET and CT both indicated 12 extranodal lymphomatous localizations. FDG-PET 
Table 7 Relation between end of treatment at CT and end of treatment at PET of the study group

\begin{tabular}{|c|c|c|c|c|c|c|c|c|c|c|c|c|}
\hline \multirow{3}{*}{$\begin{array}{l}\text { End of treatment } \\
\text { at PET }\end{array}$} & \multicolumn{8}{|c|}{ End of treatment at CT } & \multirow{2}{*}{\multicolumn{2}{|c|}{ Total }} & \multirow{2}{*}{\multicolumn{2}{|c|}{ Chi-square test }} \\
\hline & \multicolumn{2}{|c|}{ Complete regression } & \multicolumn{2}{|c|}{ Progression disease } & \multicolumn{2}{|c|}{ Partial regression } & \multicolumn{2}{|c|}{ Stationary disease } & & & & \\
\hline & No. & $\%$ & No. & $\%$ & No. & $\%$ & No. & $\%$ & No. & $\%$ & $x^{2}$ & $P$ value \\
\hline Complete regression & 5 & 25.0 & 1 & 5.0 & 1 & 5.0 & 2 & 10.0 & 9 & 45.0 & 27.005 & $<0.001^{* *}$ \\
\hline Progression disease & 0 & 0.0 & 5 & 25.0 & 0 & 0.0 & 2 & 10.0 & 7 & 35.0 & & \\
\hline Partial regression & 0 & 0.0 & 0 & 0.0 & 3 & 15.0 & 0 & 0.0 & 3 & 15.0 & & \\
\hline Stationary disease & 0 & 0.0 & 0 & 0.0 & 0 & 0.0 & 1 & 5.0 & 1 & 5.0 & & \\
\hline Total & 5 & 25.0 & 6 & 30.0 & 4 & 20.0 & 5 & 25.0 & 20 & 100.0 & & \\
\hline
\end{tabular}

$X^{2}$, Chi-square test; ${ }^{*} P$ value $<0.001 \mathrm{HS}$

This table shows statistically significant relation between end of treatment at CT and end of treatment at PET of the study group

showed 7 additional extranodal lesions while 5 additional unconfirmed lesions were observed on CT.

In a study by El Refaei et al. [17] by PET/CT, $38.5 \%$ of the studied population had complete response, 38.5\% had partial response, $10.3 \%$ had stable disease, and $12.8 \%$ had metabolic progression. Morphologic response on CT showed that $30.8 \%$ of the studied population had complete response, $48.7 \%$ had partial response, $10.3 \%$ had stable disease, and $10.3 \%$ had morphologic progression.

According to Gómez León et al. [13], the most frequent reason for the overestimation in CECT of response was the detection of residual lymphadenopathy of pathological size lacking malignant infiltration. Regarding the extra nodal lesions, the most frequent reason for incorrectly detecting lymphomatous infiltration in the lung was the detection of nonspecific inflammation

The study by Tatsumi et al. [18], 48 sites exhibited discordant findings: 34 sites as PET positive and CT negative and 14 sites as PET negative and CT positive. Among the PET-positive and CT-negative sites, patients had negative CT findings because of the size criterion (more than $10 \mathrm{~mm}$ in short axis was considered positive).

In a study done by Fueger et al. [19], PET/CT correctly diagnosed 92 nodal regions as positive for

Table 8 End of treatment distribution of the study group

\begin{tabular}{lll}
\hline CT & Number & Percent \\
Complete regression & 5 & \\
Progression disease & 6 & 25.0 \\
Partial regression & 4 & 30.0 \\
Stationary disease & 5 & 20.0 \\
PET & & 25.0 \\
Complete regression & 9 & \\
Progression disease & 7 & 45.0 \\
Partial regression & 3 & 35.0 \\
Stationary disease & 1 & 15.0 \\
\hline
\end{tabular}

lymphomatous involvement and 458 as disease free vs 68 and 449 for PET and 64 and 459 for CT, respectively. The respective sensitivities, specificities, and accuracies were $99 \%, 100 \%$, and $99.8 \%$ for PET/CT; $68 \%, 97.5 \%$, and $92.2 \%$ for PET; and $70 \%, 100 \%$, and $94.7 \%$ for CT. PET/CT performed significantly better than PET $(P<$ 0.001 for sensitivity, specificity, and accuracy) and CT ( $P$ $<0.001$ for sensitivity and accuracy). PET/CT also correctly identified significantly more extranodal lesions (22) than CT (14) and PET (nine).

In cases with PET-negative and CT-positive sites, the patients were considered to have nonviable fibrotic tissue according to clinical information, including followup imaging results.

It has been known for many years that CT assessment is not sensitive for tumoral foci that are less than $10 \mathrm{~mm}$ in diameter, but no other alternative method than size criteria has been consistently adopted.

Being aware of normal FDG distribution and physiological FDG uptake is of utter importance in oncologic PET/CT examinations. To avoid false-positive and falsenegative results, interpreting the $\mathrm{CT}$ and PET findings should be done carefully [20].

Since PET/CT provides both metabolic as well as morphologic data for each lesion, new criteria for diagnosing small foci of malignancy may be suggested with this modality.

\section{Conclusion}

PET/CT using 18F-FDG is considered one of the leading oncologic imaging modality at the present time with valuable applications in lymphoma. It is very efficient with less pitfalls and false results compared to both its components interpreted separately.

PET/CT can accurately detect the therapeutic response in lymphoma both early (interim study) as well as late (end of treatment study) with higher sensitivity than CECT as it removed the usual weaknesses of conventional imaging by combining both anatomical and metabolical information. 

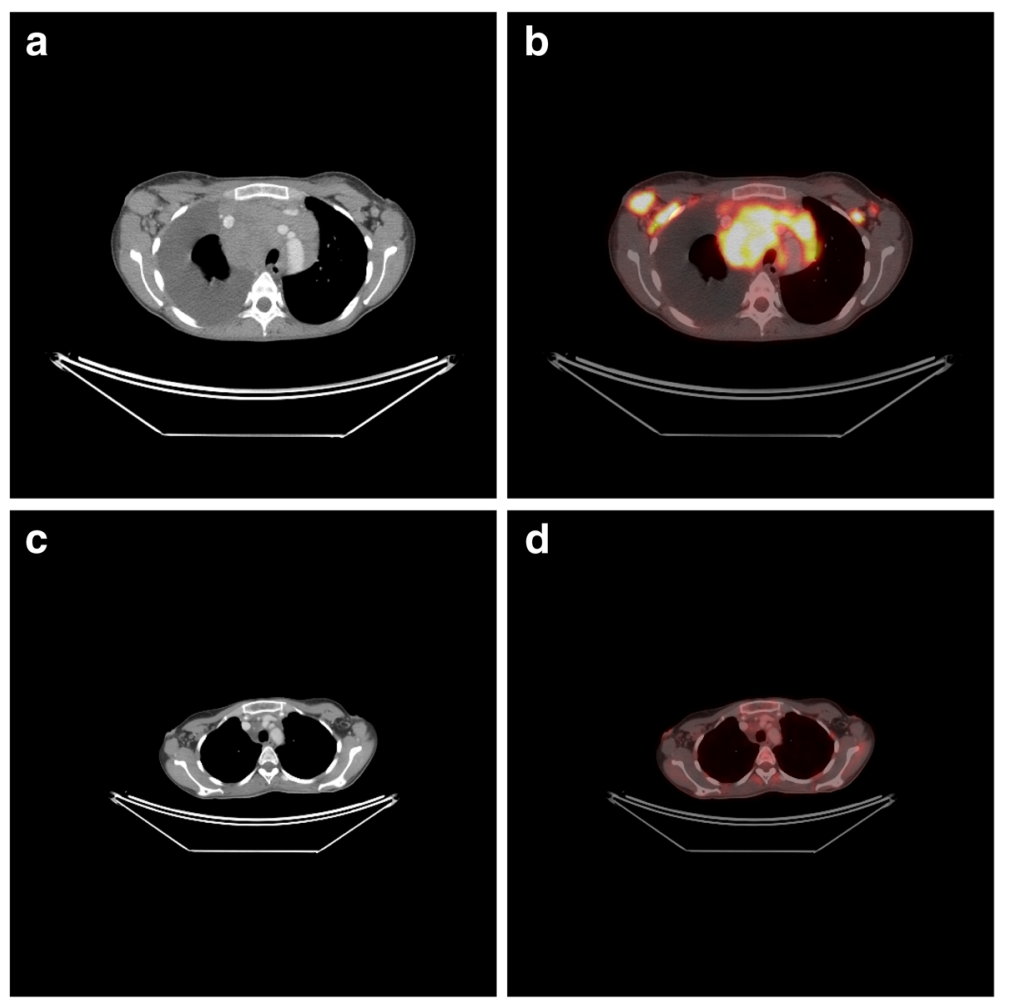

Fig. 6 A 19-year-old female patient, known case of HL. Pre-treatment PET-CT images (a, b) show multiple amalgamated hypermetabolic FDG avid lymph nodes. PET CT images at follow-up (c, $\mathbf{d})$ show marked regression of the size and the number of the lymph nodes; all of them show no metabolic activity. The patient was categorized as partial regression on $\mathrm{CT}$ and complete regression on PET/CT

We recommend using $\mathrm{PET} / \mathrm{CT}$ in assessing the treatment response in all lymphoma cases. PET/CT is becoming a standard modality for lymphoma providing a new vision to management and treatment plan.

We acknowledge some limitations in current study as small number of subjects enrolled in this study and the lack of biopsy. Also, the patient population studied was heterogeneous, and larger studies evaluating the individual subtypes might be needed to confirm our results.

\section{Abbreviations}

CR: Complete responses; PR: Partial responses; PD: Progressive diseases; PET/ CT: Positron emission tomographic/Computed tomographic;

FDG: Fluorodeoxyglucose; PET: Positron emission tomographic;

CT: Computed tomographic; CECT: Contrast-enhanced computed tomography

\section{Acknowledgements}

Not applicable

\section{Authors' contributions}

A. Y. revised the results and was a major contributor in writing the manuscript. M. A. revised patients' data and was a major contributor in writing the manuscript. R. H. collected analyzed and interpreted the patient data. All authors read and approved the final manuscript.

\section{Funding}

No funds, sponsorship, or financial support to be disclosed

\section{Availability of data and materials}

The datasets used and/or analyzed during the current study are available from the corresponding author on reasonable request.

\section{Ethics approval and consent to participate}

Not applicable. This was a retrospective study. We collected the data from the records of the patients and the institutional review board waived the requirement for informed patient consent.

Approval no. FMASU R 91/2020

\section{Consent for publication}

All patients included in this research were fully conscious and older than 16 years old and gave written informed consent to publish the data contained within this study.

\section{Competing interests}

The authors declare that they have no competing interest.

Received: 12 July 2020 Accepted: 8 November 2020 Published online: 27 November 2020

\section{References}

1. De Angelis R, Sant M, Coleman MP et al (2014) Cancer survival in Europe 1999-2007 by country and age: results of EUROCARE-5 - a populationbased study. Lancet Oncol 15:23-34. https://doi.org/10.1016/s14702045(13)70546-1

2. Kobe C, Dietlein M, Hellwig D (2017) PET/CT for lymphoma post-therapy response assessment in Hodgkin lymphoma and diffuse large B-cell lymphoma. https://doi.org/10.1053/j.semnuclmed.2017.09.003

3. Barrington SF, Kluge R (2017) FDG PET for therapy monitoring in Hodgkin and non-Hodgkin lymphomas. Eur J Nucl Med Mol Imaging 44(Suppl 1):97110. https://doi.org/10.1007/s00259-017-3690-8 
4. Kobayashi K, Bhargava P, Raja S et al (2012) Image-guided biopsy: what the interventional radiologist needs to know about PET/CT. Radiographics 32: 1483-1501. https://doi.org/10.1148/rg.325115159

5. Fallanca F, Alongi P, Incerti E et al (2016) Diagnostic accuracy of FDG PET/ $\mathrm{CT}$ for clinical evaluation at the end of treatment of $\mathrm{HL}$ and $\mathrm{NHL}$ : a comparison of the Deauville criteria (DC) and the International Harmonization Project Criteria (IHPC). Eur J Nucl Med Mol Imaging 43(10): 1837-1848. https://doi.org/10.1007/s00259-016-3390-9

6. Hutchings M, Barrington SF (2009) PET/CT for therapy response assessment in lymphoma. J Nucl Med 50(Suppl 1):21S-30S. https://doi.org/10.2967/ jnumed.108.057190

7. Follows GA, Ardeshna KM, Barrington SF et al (2014) The British Committee for Standards in Haematology Guidelines for the first line management of classical Hodgkin lymphoma. Br J Haematol 166(1):34-49. https://doi.org/10. 1111/bjh.12878

8. Johnson SA, Kumar A, Matasar MJ et al (2015) Imaging for staging and response assessment in lymphoma. Radiology 276(2):323-338. https://doi. org/10.1148/radiol.2015142088

9. Cheson BD, Fisher Rl, Barrington SF (2014) Recommendations for initial evaluation, staging, and response assessment of Hodgkin and non-Hodgkin lymphoma: the Lugano classification. J Clin Oncol 32(27):3059-3068. https:// doi.org/10.1200/jco.2013.54.8800

10. Okada M, Sato N, Ishii K, Matsumura K, Hosono M, Murakami T: FDG PET/CT versus $C T$, MR imaging, and ${ }^{67} \mathrm{Ga}$ scintigraphy in the posttherapy evaluation of malignant lymphoma. Radiographics 2010;30(4). doi: https://doi.org/10. 1148/rg.304095150

11. Omar NN, Alotaify LM et al (2016) PET/CT in initial staging and therapy response assessment of lymphoma. Egypt J Radiol Nucl Med. https://doi. org/10.1016/j.ejrnm.2016.07.009

12. Cronin C, Sword R, Truong M et al (2010) Clinical utility of PET/CT in lymphoma. AJR 194:91-103. https://doi.org/10.2214/ajr.09.2637

13. Gómez León N, Delgado-Bolton RC, del Campo del Val L et al (2017) Multicenter comparison of contrast-enhanced FDG PET/CT and 64-slice multi-detector-row $\mathrm{CT}$ for initial staging and response evaluation at the end of treatment in patients with lymphoma. Clin Nucl Med 1. https://doi. org/10.1097/rlu.0000000000001718

14. Othman AIA, Nasr M, Abdel-Kawi M (2019) Beyond lymph nodes: ${ }^{18}$ F-FDG $\mathrm{PET} / \mathrm{CT}$ in detection of unusual sites of extranodal lymphoma. Egypt J Radiol Nucl Med 50:29. https://doi.org/10.1186/s43055-019-0011-1

15. Le Dortz L, De Guibert S, Bayat S et al (2010) Diagnostic and prognostic impact of 18F-FDG PET/CT in follicular lymphoma. Eur J Nucl Med Mol Imaging 37:2307-2314. https://doi.org/10.1007/s00259-010-1539-5

16. Najjar F, Hustinx R, Jerusalem G, Fillet $G$, Rigo $P$ (2001) Positron emission tomography (PET) for staging low-grade non-Hodgkin's lymphomas (NHL). Cancer Biother Radiopharm 16(4):297-304. https://doi.org/10.1089/ 108497801753131372

17. El Refaei S, Abougabal M, Salama R et al (2018) The predictive value of PETscan in diffuse large B-cell in optimizing the treatment decision. Cancer Biol 8(4):63-70. https//doi.org/10.1097/01.hs9.0000565852.22530.6f ISSN: 2150-1041

18. Tatsumi M, Cohade C, Nakamoto $Y$ et al (2005) Direct comparison of FDG PET and $C T$ findings in patients with lymphoma: initial experience. Radiology 237(3):1038-1045. https://doi.org/10.1148/radiol.2373040555

19. Fueger BJ, Yeom K, Czernin J, Sayre JW, Phelps ME, Allen-Auerbach MS (2009) Comparison of CT, PET, and PET/CT for staging of patients with indolent non-Hodgkin's lymphoma. Mol Imaging Biol 11(4):269-274. https:// doi.org/10.1007/s11307-009-0200-9

20. Meirelles PG, Capobianco J, Condé de Oliveira MA (2017) Pitfalls and artifacts in the interpretation of oncologic PET/CT of the chest. Radiol Bras 50(1):55-59. https://doi.org/10.1590/0100-3984.2015.0194

\section{Publisher's Note}

Springer Nature remains neutral with regard to jurisdictional claims in published maps and institutional affiliations.

\section{Submit your manuscript to a SpringerOpen ${ }^{\circ}$ journal and benefit from:}

- Convenient online submission

- Rigorous peer review

- Open access: articles freely available online

- High visibility within the field

- Retaining the copyright to your article

Submit your next manuscript at $\boldsymbol{\nabla}$ springeropen.com 